Supplement of Eur. J. Mineral., 33, 221-232, 2021

https://doi.org/10.5194/ejm-33-221-2021-supplement

(C) Author(s) 2021. CC BY 4.0 License.

(c) (i)
European Journal of

Mineralogy

Open Access

Supplement of

\title{
A gemmological study of the reliquary crown of Namur, Belgium
}

Yannick Bruni et al.

Correspondence to: Yannick Bruni (yannick.bruni@uliege.be)

The copyright of individual parts of the supplement might differ from the article licence. 
Table S1: List with all Raman bands of gemstones and pearls analysed. Numbers in bold denote strong bands.

\begin{tabular}{cccc}
\hline Sample & Phase & Colour & Raman peaks $/ \mathbf{b a n d s ~}\left(\mathbf{c m}^{-1} \mathbf{)}\right.$ \\
\hline P1-6 & Emerald & Green & $320 ; 398 ; 522 ; \mathbf{6 8 6} ; 1010 ; 1070$ \\
P5-6 & Emerald & Green & $318 ; 394 ; 520 ; \mathbf{6 8 4} ; 1012 ; 1068$ \\
\hline P3-4 & Sapphire & Blue & $374 ; \mathbf{4 1 4} ; 640 ; 740$ \\
P4-3 & Sapphire & Blue & $370 ; \mathbf{4 1 4} ; 564 ; 648 ; 746$ \\
\hline P3-1 & Garnet & Red & $344 ; 490 ; 550 ; 624 ; 854 ; \mathbf{9 1 4} ; 1040$ \\
P4-1 & Garnet & Red & $348 ; 490 ; 552 ; 624 ; 854 ; \mathbf{9 1 6} ; 1042$ \\
P5-3 & Garnet & Red & $346 ; 492 ; 550 ; 626 ; 856 ; \mathbf{9 1 6} ; 1040$ \\
P6-3 & Garnet & Red & $348 ; 494 ; 550 ; 626 ; 858 ; \mathbf{9 1 8} ; 1044$ \\
P1-2 & Spinel & Pink & $\mathbf{4 0 2} ; 668 ; 760$ \\
P8-3 & Spinel & Pink & $308 ; \mathbf{4 0 4} ; 660 ; 764$ \\
P2-1 & Pearl & White & $162 ; 204 ; 706 ; 1086$ \\
P4-5 & Pearl & White & $158 ; 202 ; 706 ; \mathbf{1 0 8 6}$ \\
P5-5 & Pearl & White & $158 ; 200 ; 708 ; \mathbf{1 0 8 6}$ \\
P7-5 & Pearl & White & $156 ; 198 ; 710 ; \mathbf{1 0 8 8}$ \\
\hline
\end{tabular}


Figure S1
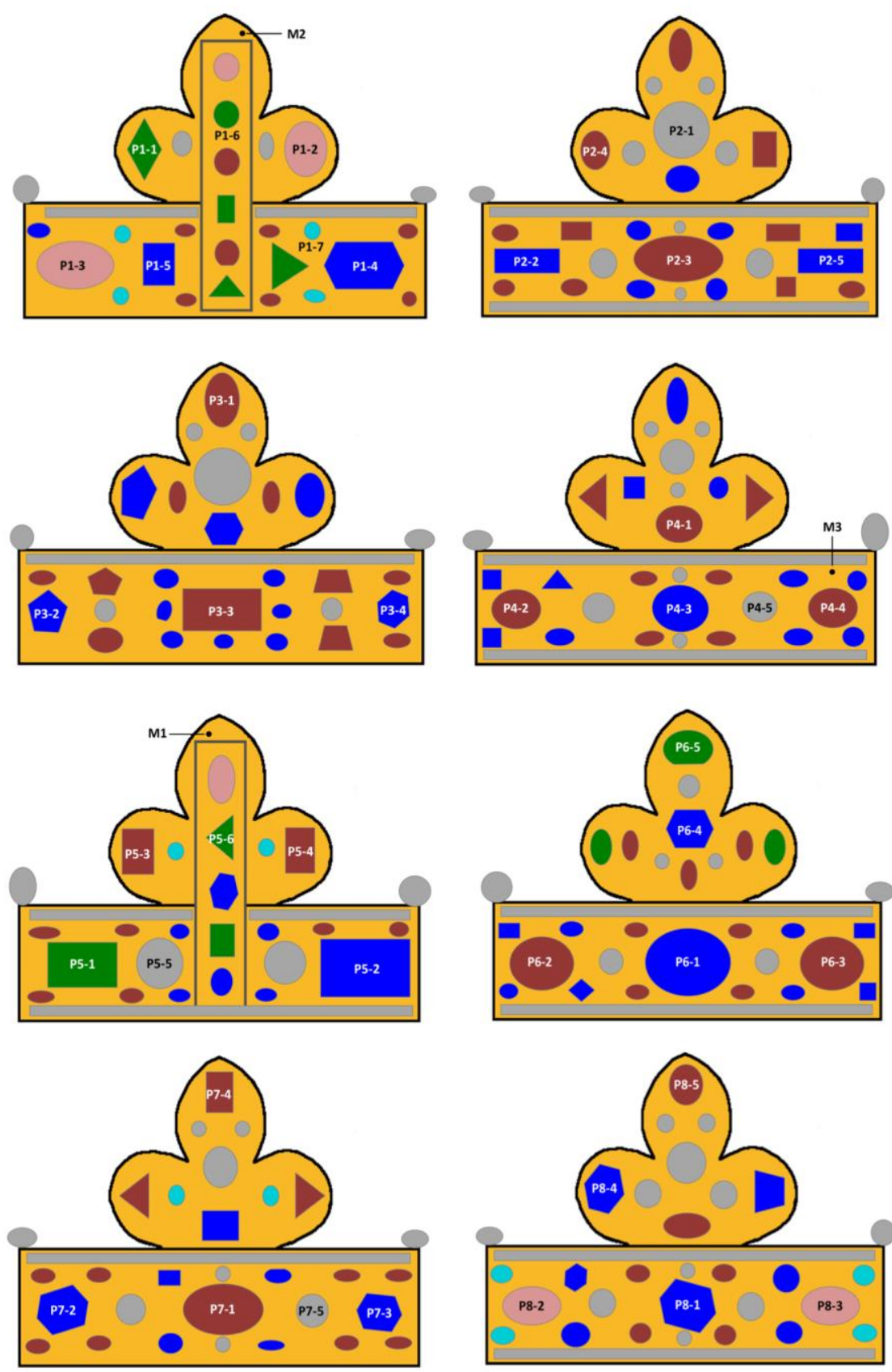